\title{
Synthesis of sterculic acid
}

\author{
Juan Hernando, M. Paz Matía, J. Luis Novella, and Julio Alvarez-Builla* \\ Planta Piloto de Química Fina, Universidad de Alcalá, 28871 Alcalá de Henares \\ Madrid, Spain \\ E-mail:julio.alvarez@uah.es
}

\section{Dedicated to Professor Marcial Moreno-Manas on his $60^{\text {th }}$ anniversary \\ (received 27 Sep 01; accepted 28 Jan 02; published on the web 05 Feb 02)}

\begin{abstract}
Sterculic acid, a cyclopropene fatty acid, present in the seed oil of several species, has been synthesized on $10 \mathrm{~g}$ scale, based on the addition of ethyl diazoacetate on an alkyne derivative.
\end{abstract}

Keywords: Sterculic acid, methylstearolate

\section{Introduction}

Naturally occurring three-membered ring compounds are endowed with a large spectrum of biological properties, ranging from insecticidal, antifungal, antibiotic, antiviral, herbicidal, hormonal, carcinogenic or antitumoral activities, enzyme and gluconeogenesis inhibitions to neurochemical activity. ${ }^{1,2}$ Among them, two cyclopropene fatty acids, sterculic and malvalic acids (Fig. 1), which are present in seed oil of various species, including Sterculia or the common cotton plant, Gossypium hirsutum, are potent inhibitors of the $\Delta^{9}$-desaturation of stearic to oleic acid. ${ }^{3,4}$ Additionally, both acids inhibit the $\Delta^{9}$-desaturation of different C-12 to C-20 aliphatic acids. ${ }^{5}$

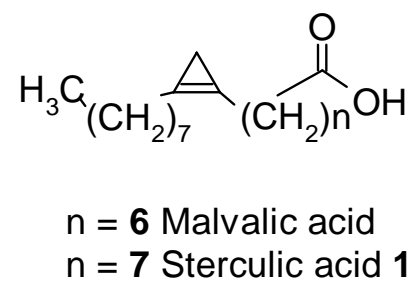

Figure 1 
On the basis of degradation experiments Nunn ${ }^{6}$ proposed the structure 9,10-methano-9octadecenoic acid for sterculic acid. Some reported syntheses of sterculic acid and the lower homologue, malvalic acid, are based on the addition of a methylene unit to an alkyne, ${ }^{7-9}$ the alkylation of a lithiocyclopropene ${ }^{10}$ or the deiodination of 1,2-diiodocyclopropanes. ${ }^{11}$

\section{Results and Discussion}

As a part of a general project on lipid metabolism, a synthesis of sterculic acid has been developed, based on previous methods, at a $10 \mathrm{~g}$ scale, that includes reaction of methyl stearolate 3 and ethyldiazoacetate, to obtain the cyclopropene unit, with an overall yield in the last two steps (6-7-1, Scheme 1) of 45\%, from commercial stearolic acid. A related route has been reported previously to provide methyl sterculate with a $20 \%$ yield in the same steps, at a scale of $0.5 \mathrm{~g}$ of the final product. ${ }^{12}$

Methyl stearolate and ethyl diazoacetate reacted in the presence of copper bronze to form 2(7-methoxycarbonylheptyl)-3-octylcycloprop-2-ene carboxylic acid ethyl ester 4. Hydrolysis of 4 , followed by treatment with thionyl chloride gave the corresponding diacyl chloride $\mathbf{6}$. This product, exposed to anhydrous zinc chloride, underwent decarbonylation, generating the cyclopropenium acid chloride intermediate 7. After esterification with methanol, the resulting cyclopropenium ion was reduced with sodium borohydride to give sterculic acid (45\% yield) and traces of methyl sterculate. An alternate method was tested, ${ }^{13,9}$ for direct decarbonylation of 4, by employing chlorosulfonic acid. The obtained cyclopropenium derivative 7 yielded sterculic acid with an overall yield, in the steps 4-7-1, of $20 \%$ in $0.5 \mathrm{~g}$ scale, but this falls to $10 \%$ at the $5 \mathrm{~g}$ scale.

In conclusion, a reliable method of synthesis of sterculic acid $\mathbf{1}$, has been developed and scaled up to afford $10 \mathrm{~g}$ of the final product. The method can be used to produce sterculic acid derivatives, useful in fatty acid metabolism studies.

\section{Experimental Section}

General Procedures. Column chromatography was performed on silica gel Merck 60 (70-230 mesh) using the specified eluent. All solvents were used in p.a. quality and, when necessary, were dried by standard methods. ${ }^{1} \mathrm{H}$ NMR spectra were recorded on a Varian Gemini spectrometer $(300 \mathrm{MHz})$ in $\mathrm{CDCl}_{3}$ with $\mathrm{TMS}$ as an internal standard. ${ }^{13} \mathrm{C} \mathrm{NMR}$ spectra were recorded on a Varian Gemini spectrometer $(75 \mathrm{MHz})$ in $\mathrm{CDCl}_{3}$ with $\mathrm{TMS}$ as an internal standard. IR spectra was recorded as KBr pellets using a Nicolet Impact-410 spectrophotometer. The elemental analysis was performed by the UCSA of the Universidad de Alcalá. 
Hex-3-ynoic acid methyl ester (3). A $3 \mathrm{~L}$ reactor was charged with $150 \mathrm{~g}(0.535 \mathrm{~mol})$ of stearolic (hex-3-ynoic) acid 2, dissolved in methanol $(1.5 \mathrm{~L})$. The mixture was stirred at room temperature, thionyl chloride $(19 \mathrm{~mL})$ was added, and stirring was maintained for 3 hours. Then, the mixture was concentrated under reduced pressure, yielding methyl stearolate as a brown oil $(99 \%)$ which was used without further purification. ${ }^{1} \mathrm{H} \mathrm{NMR}\left(\mathrm{CDCl}_{3}, 300 \mathrm{MHz}\right): \delta 3.65(\mathrm{~s}, 3 \mathrm{H})$, 2.31-2.10 (m, 6H), 1.63-1.26 (m, 22H), 0.87 (t, 3H, J=6.85 Hz).

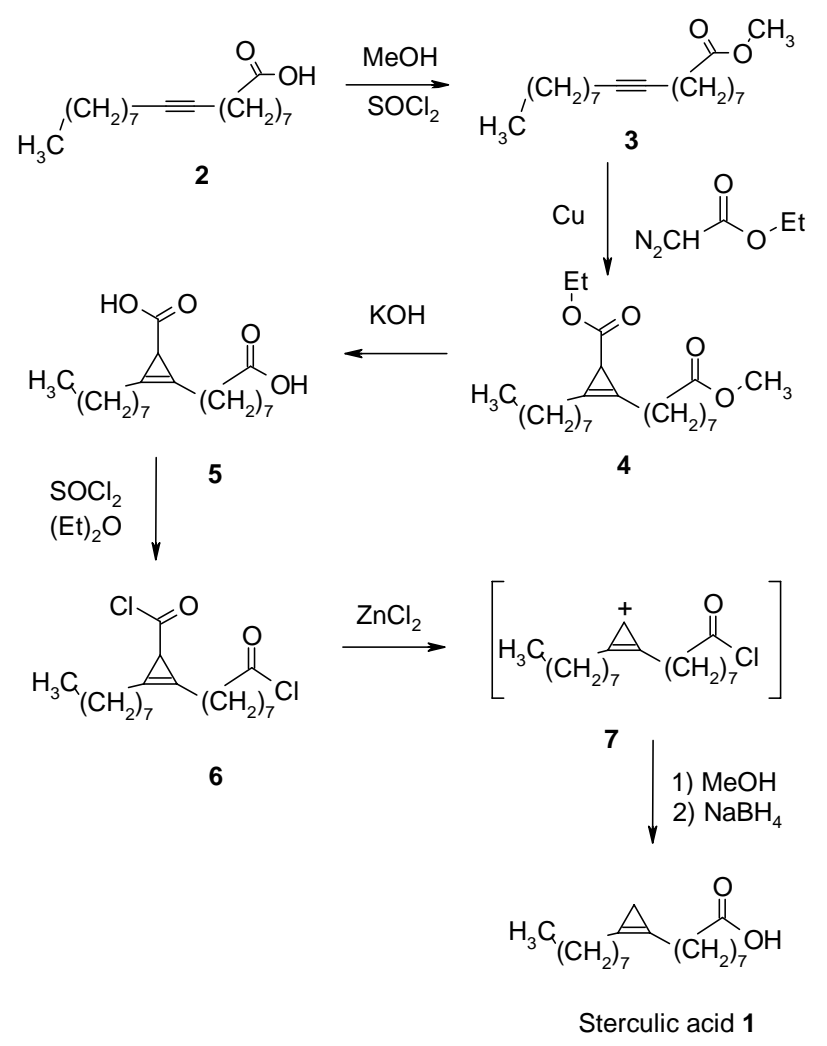

\section{Scheme 1}

2-(Methoxycarbonyl-heptyl)-3-octylcycloprop-2-enecarboxylic acid ethyl ester (4). A $500 \mathrm{~mL}$, three-necked flask was charged with $100 \mathrm{~g}(0.34 \mathrm{~mol})$ of methyl stearolate 3 and $7.8 \mathrm{~g}$ of powdered cooper bronze. After replacing the air in the flask with nitrogen, the flask was placed in an oil bath preheated to $130-135^{\circ} \mathrm{C}$, and ethyl diazoacetate $(71.4 \mathrm{~mL}, 0.679 \mathrm{~mol})$ was added drop wise to the stirred mixture, care being taken to make the drops fall directly into the reaction mixture, avoiding preliminary contact with the side wall of the flask. After addition of all the diazoacetate $(2.5 \mathrm{~h})$ the reaction mixture was heated and stirred for another 3 hours. The crude product was filtered and the residue was chromatographed on silica gel (hexane:diethyl ether, 4:1). The resulting oil weighed $62.8 \mathrm{~g}(49 \%)$. ${ }^{1} \mathrm{H} \mathrm{NMR}\left(\mathrm{CDCl}_{3}, 300 \mathrm{MHz}\right): \delta 4.09$ (q, 2H, $J=7.25 \mathrm{~Hz}), 3.65$ (s, 3H), 2.40-2.26 (m, 6H), 2.00 (s, 1H), 1.62-1.19 (m, $22 \mathrm{H}), 0.87$ (t, 3H, $J=7.25 \mathrm{~Hz}$ ). 
2-(7-Carboxyheptyl)-3-octyl-cycloprop-2-enecarboxylic acid (5). A $500 \mathrm{~mL}$ flask was charged with $36 \mathrm{~g}(0.095 \mathrm{~mol})$ of the diester 4 , ethanol $(200 \mathrm{~mL})$ and $50 \mathrm{~g}(0.75 \mathrm{~mol}) \mathrm{of} \mathrm{KOH}$. The mixture was stirred and refluxed for 1.5 hours. Then, it was treated with $35 \% \mathrm{HCl}$ up to $\mathrm{pH}=1$, diluted with water $(200 \mathrm{~mL})$ and extracted with diethyl ether $(2 \times 50 \mathrm{~mL})$. The ether solution was dried with sodium sulfate, and the solvent removed leaving an orange oil (quantitative) which was used without further purification. ${ }^{1} \mathrm{H} \mathrm{NMR}\left(\mathrm{CDCl}_{3}, 300 \mathrm{MHz}\right): \delta 12.00$ (s, 2H), 2.42-2.30 (m, 6H), $2.02(\mathrm{~s}, 1 \mathrm{H}), 1.64-1.18(\mathrm{~m}, 22 \mathrm{H}), 0.87$ (t, 3H, J=6.85 Hz).

2-(7-Chlorocarbonyl-heptyl)-3-octyl-cycloprop-2-ene carbonyl chloride (6). A $500 \mathrm{~mL}$ flask was charged with $32 \mathrm{~g}(0.094 \mathrm{~mol})$ of diacid 5, dissolved in $300 \mathrm{~mL}$ of dry diethyl ether and, in the absence of light and at room temperature, $26.7 \mathrm{~mL}(0.369 \mathrm{~mol})$ of thionyl chloride were added. The mixture was stirred for 4.5 hours, the solvent was distilled under reduced pressure, and the dichloride 6 appeared as a brown oil (33 g, 93\%) which was used without further purification. ${ }^{1} \mathrm{H} \mathrm{NMR}\left(\mathrm{CDCl}_{3}, 300 \mathrm{MHz}\right): \delta 2.87$ (t, $\left.2 \mathrm{H}, J=7.22 \mathrm{~Hz}\right), 2.47-2.33(\mathrm{~m}, 6 \mathrm{H}), 2.00(\mathrm{~s}$, $1 \mathrm{H}), 1.69-1.25(\mathrm{~m}, 22 \mathrm{H}), 0.86(\mathrm{t}, 3 \mathrm{H}, J=6.83 \mathrm{~Hz})$.

8-(2-Octyl-cycloprop-1-enyl)-octanoic acid (1). Decarbonylation was obtained by stirring a mixture of the acid chloride 6 (10.8 g, $0.029 \mathrm{~mol})$, anhydrous zinc chloride $(3.9 \mathrm{~g}, 0.029 \mathrm{~mol})$ and $100 \mathrm{~mL}$ of dichloromethane, in the absence of light and at room temperature. Dry nitrogen was bubbled through the reaction mixture during the process. After 4 hours, the dark purple mixture was cooled to $3{ }^{\circ} \mathrm{C}$, and $1.2 \mathrm{~mL}(0.029 \mathrm{~mol})$ of absolute methanol was added. The mixture was stirred at this temperature for 1 hour. To reduce the cyclopropene carbonium ion 7 , the previous mixture was poured over a vigorously stirred solution of sodium borohydride $(5.4 \mathrm{~g}$, $0.143 \mathrm{~mol})$ and sodium hydroxide $(2.46 \mathrm{~g})$ in $125 \mathrm{~mL}$ of anhydrous methanol, over a period of 55 minutes, at $-33{ }^{\circ} \mathrm{C}$. The purple colour disappeared very quickly, and the reaction mixture turned to yellow. After 15 additional minutes of stirring at $-33^{\circ} \mathrm{C}$, and 30 minutes at room temperature, the reaction mixture was treated with $200 \mathrm{~mL}$ of water and then with ca. $99 \mathrm{~mL}$ of $10 \% \mathrm{HCl}$ (to obtain $\mathrm{pH}=4)$. The mixture was extracted with dichloromethane and sequentially washed with: water, $10 \% \mathrm{NaHCO}_{3}$, water and saturated $\mathrm{NaCl}$ solution. The organic layer was dried with sodium sulfate, and then evaporated under reduced pressure. The remaining oil was chromatographed over silica (hexane:diethyl ether, 3:1). The sterculic acid 1 was obtained as a colorless oil (3.80 g, $45 \%) .{ }^{1} \mathrm{H}$ NMR $\left(\mathrm{CDCl}_{3}, 300 \mathrm{MHz}\right): \delta 2.39-2.32(\mathrm{~m}, 6 \mathrm{H}), 1.65-1.51(\mathrm{~m}$, $6 \mathrm{H}), 1.32-1.27(\mathrm{~m}, 16 \mathrm{H}), 0.87(\mathrm{t}, 3 \mathrm{H}, \mathrm{J}=6.5 \mathrm{~Hz}), 0.76(\mathrm{~s}, 2 \mathrm{H}) .{ }^{13} \mathrm{C} \mathrm{NMR}\left(\mathrm{CDCl}_{3}, 75 \mathrm{MHz}\right): \delta$ $179.0,109.1,108.9,33.6,31.5,30.5,29.0,28.9,28.8,28.7,27.0,26.9,25.7,25.6,24.3,22.3$, 13.7, 7.0. IR ( . $\left.\max , \mathrm{cm}^{-1}\right): 2927,2856,1735,1715,1458,1428,1361,1284,1219$, and 1007. Anal. Calcd. for $\mathrm{C}_{19} \mathrm{H}_{34} \mathrm{O}_{2}$ : C, 77.49; H, 11.63. Found: C, 77.49; H, 11.78.

\section{Acknowledgements}

Authors wish to thank Sanofi-Synthelabo for financial support through the Fundación General de la Universidad de Alcalá. 


\section{References and Notes}

1. Salaun, J.; Baird, M. S. Curr. Med Chem. 1995, 2, 511.

2. Salaun, J.; Top. Curr. Chem. 2000, 207, 1.

3. Johnson, A. R.; Pearson, J. A.; Shenstone, F. S.; Fogerty, A. C. Nature 1967, 214, 1244.

4. Quintana, J.; Barrot, M.; Fabrias, G.; Camps, F. Tetrahedron 1998, 54, 10187.

5. Johnson, A. R.; Fogerty, A. C.; Pearson, J. A.; Shenstone, F. S.; Bersten, A. M. Lipids 1968, 4, 265.

6. Nunn, J. R. J. Chem. Soc. 1952, 313.

7. Gensler, W.; Floyd, M. B.; Yanase, R.; Pober, K. W. J. Am. Chem. Soc. 1970, 92, 2472.

8. Gensler, W.; Pober, K. W.; Solomon, D. M.; Floyd, M. B. J. Org. Chem. 1970, 35, 2301.

9. Williams, J. L.; Sgoutas, D. S. J. Org. Chem. 1971, 36, 3064.

10. Baird, M. S.; Dale, C. M., Lytollis, W.; Simpson, M. J. Tetrahedron Lett. 1992, 33, 1521.

11. Baird, M. S.; Grehan, B. J. Chem. Soc., Perkin Trans. 1 1993, $14,1547$.

12. Gensler, W. J.; Floyd, M. B.; Yanase, R.; Pober, K. J. Am. Chem. Soc. 1969, 91, 2397.

13. Williams, J. L.; Sgoutas, D. S. Chem. Phys. Lipids 1972, 9, 295. 